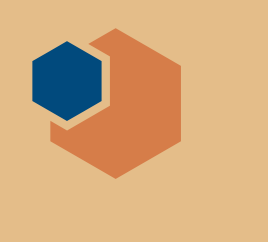

\section{UK and European materials researchers concerned about Brexit}

$\mathrm{M}$ aterials researchers in the UK are lamenting the possible loss of an important source of funding for new infrastructure as the government struggles to agree on the terms of its departure from the EU. They are also concerned about the funding regime after the end of the Horizon 2020 (H2020) program. The latest in a series of long-running Framework Programs for the support of research, H2020 started in 2014 and is due to run to 2020 with nearly $€ 80$ billion of funding available over the program's seven years.

Two years on since the UK voted to leave the EU, the timing of the divorceknown as Brexit - originally due at the end of March, remains undecided as of mid-May (when this report is written). The UK government has yet to clarify the fate of these important funding streams. Much will depend on the new relationship that the UK establishes with the EU. Will Brexit researchers remain closely linked to H2020, with the UK matching its current contribution and negotiating a research treaty? Or will it be what is known as a "hard Brexit," leaving the UK in the same position as other researchers?

The nature of the final agreement will affect not only H2020 and its follow-on, but also regional funding initiatives. For example, the UK's National Graphene Institute (NGI) alone received $£ 23$ million through the European Fund for Regional Development (ERDF), another source of EU funding available to materials research groups. The ERDF, a part of the European Structural and Investment Funds Growth program, set out to support "research and innovation, small- to medium-sized enterprises and the creation of a low carbon economy." The ERDF supports funds and activities that reduce economic disparity within the EU's Member States.

The NGI, situated in Manchester, also received UK government development support under what is dubbed the "Northern powerhouse," an attempt to breathe life back into the north of England, a region that, like the so-called rust belt regions in the United States, lost out economically during the decline of manufacturing. Another

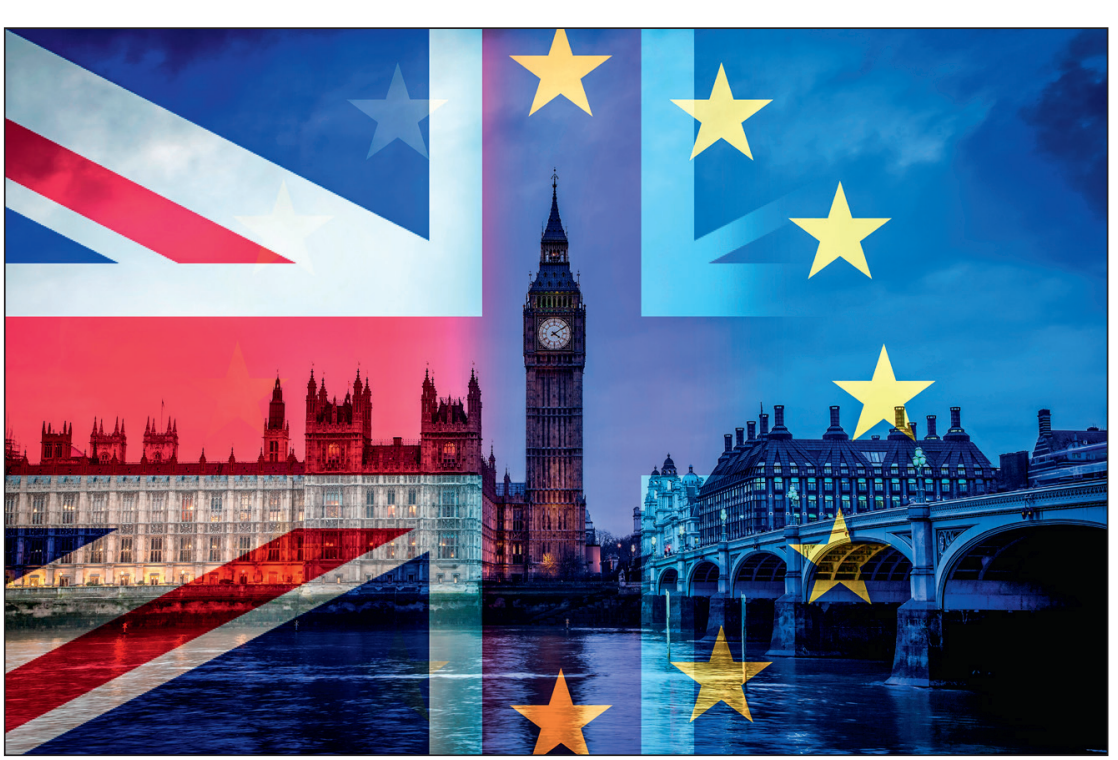

beneficiary of ERDF support in the north of England is the Royce Translational Centre in Metal Alloy Powder-to-Part Manufacture at Royce@Sheffield, The University of Sheffield wing of the Sir Henry Royce Institute. The fund provided setup costs of $£ 4$ million, about half the cost of the Royce Translational Centre.

Mark Rainforth, director and principal investigator championing the Advanced Metals Processing theme at Royce@ Sheffield, says that while the "EU monies received on Royce are in the past" and will have no effect, "in the future I am sure Brexit will affect us in all sorts of ways." His view is that "the loss of regional development funds will be a problem. These have been a key funding source over the last decades."

Rainforth is also concerned about the impact on recruitment. "We rely on multinational workers. It is simply impossible to deliver with UK researchers only as there simply are not enough people around." So far the biggest impact has been on attracting undergraduate students. When it comes to researchers, recruitment at The University of Sheffield has been satisfactory, he adds, "but that may well change."

It is not just the fate of research institutes such as the NGI and Royce that face an uncertain future as Brexit looms. There are serious concerns surrounding some of the EU's major initiatives. For example, it has invested heavily in graphene R\&D through the Graphene Flagship (see MRS Bulletin, February 2017). One of the Future and Emerging Technologies (FET) flagships, this initiative has a budget of $€ 1$ billion. The Graphene Flagship describes itself as "a new form of joint, coordinated research on an unprecedented scale, forming Europe's biggest ever research initiative."

The EU's FET flagships are long-term programs that require sustained support for up to 10 years. They operate through "coordinated efforts between the EU and its Member States' national and regional programmes." Announced at the beginning of 2013, and with a roadmap that talks of a "vision beyond 2023," this timetable takes the Graphene Flagship long beyond the UK's expected departure from the EU, although when this will actually 
happen is far from certain. This is why the flagship, coordinated by Chalmers University of Technology in Gothenburg, Sweden, set up a working group on what might happen post-Brexit not long after the UK's vote to leave the EU.

"We have had a Brexit committee running for some $1 \frac{1}{2}$ years by now, with representatives from partners in the UK and in the rest of the EU," says Jari Kinaret, director of the Graphene Flagship. "UK organizations are valued partners in the Graphene Flagship, representing some $15-20 \%$ of the flagship's budget, perhaps a little more than that in the fundamental topics and a little less in the more applied fields."

The flagship's working party has, says Kinaret, "identified roughly one dozen possible scenarios that might happen and outlined the actions that we would need to take in those cases." The challenge has been to prepare for those scenarios in time. Just weeks before the date initially planned for the UK to leave the EU, there was no guidance on the likely course of events. As Kinaret says, "Some of the actions we would need to take in the case of a hard Brexit require quite some time to implement." For example, there would have to be new agreements, involving 150 partners, on intellectual property rights.

While Kinaret is unwilling to go into details on the scenarios and possible actions, he says that "our goal is to continue working closely with them [UK organizations] after the Brexit. How this collaboration will be shaped depends on the political arrangements between the UK and the EU, and it is too early to speculate on the specifics."

There are precedents for researchers outside the EU to participate in the work of the Graphene Flagship. It already has partners in so-called associated countries, Norway and Switzerland, along with Belarus, which has an agreement that allows it to participate in some EU research projects. However, as Kinaret points out, developed third countries, which the UK would become if it left the EU with no agreement on links after Brexit, "are usually not eligible to be funded through EU research projects unless there are specific agreements."

Michael Kenward
US and Israel issue call for proposals for energy center birdf.com/energycenter

$\mathrm{T}_{1}$ he US Department of Energy (DOE), Israel's Ministry of Energy, and the Israel Innovation Authority have announced a call for proposals for a U.S.-Israel Center of Excellence in Energy, Engineering and Water Technology (Energy Center). The Center, which resides under the Israel-U.S. Binational Industrial Research and Development Foundation (BIRD), will initially fund up to USD\$16 million for research in the areas of the energy-water nexus, fossil energy, energy storage, and cybersecurity.
The US and Israeli governments will provide USD\$8 million each for the initial two-year launch of the Center.

The goal of the Center is to promote energy security and economic development through the R\&D of innovative energy technologies, while facilitating cooperation among consortia of US and Israeli companies, research institutes, and universities.

The submission deadline for full proposals is August 15, 2019. More information on the call for proposals and how to apply can be found on the BIRD Foundation website.

The establishment of a joint USIsrael energy center was first authorized by the US Congress in the United States-Israel Strategic Partnership Act of 2014. In February of this year, DOE announced the BIRD Foundation as the operating agent of the Center. The BIRD Foundation was established by the US and Israeli governments in 1977 to generate mutually beneficial cooperation between US and Israeli companies, including startups and established organizations. DOE manages the BIRD Foundation's BIRD Energy program for the US side.

South Africa and China begin student exchange program dst.gov.za

$\mathrm{T}_{\mathrm{s}}^{\mathrm{s}} \mathrm{sin}$ he South Africa-China Young Scientists Exchange Programme is based on a five-year agreement signed by the South African Department of Science and Technology and the Chinese Ministry of Science and Technology in 2017, to give young researchers from both countries an opportunity to share knowledge and develop skills. The first group of students have begun the exchange this spring. The program will promote the development of scientists, scholars, and researchers, focusing on various scientific fields including biotechnology, advanced manufacturing, ICT systems, green technologies, the exploitation of mineral resources, and space science and astronomy.

The Young Scientists Exchange Programme is jointly funded with the aim of cultivating future scientist leaders, by promoting the exchange of researchers between research institutes, universities, and enterprises in an effort to advance $\mathrm{R} \& \mathrm{D}$, and produce academic papers, new patents, and innovative products.

The majority of the successful students, selected through a call issued by the South African National Research Foundation earlier this year, come from historically disadvantaged institutions. The students who have been selected in the spring will spend up to 12 months at universities across China. 